\title{
49,XXXXY: a distinct phenotype. Three new cases and review
}

Jennifer Peet, David D Weaver, Gail H Vance

\begin{abstract}
Over 100 cases of $49, \mathbf{X X X X Y}$ syndrome have been published to date. Classic findings include radioulnar synostosis, hypogonadism, and mental retardation. The majority of reported cases have not distinguished the 49,XXXXY syndrome from Klinefelter syndrome $(47, \mathrm{XXY})$, and these patients are frequently labelled as having Klinefelter syndrome or as being a "Klinefelter variant." Because of distinct clinical features, we delineate the $49, \mathrm{XXXXY}$ syndrome as separate from Klinefelter syndrome, and emphasise the prevalence of congenital heart defects. We also report three new cases of $49, \mathbf{X X X X Y}$ syndrome and briefly discuss patient management.

$(\Im$ Med Genet 1998;35:420-424)
\end{abstract}

Keywords: sex chromosome; Klinefelter syndrome; aneuploidy

The 49,XXXXY syndrome was first reported in 1960 by Fraccaro et al ${ }^{\prime}$ and represents a rare sex chromosome aneuploidy syndrome with an approximate incidence of 1 in 85000 male births. ${ }^{2}$ A $49, \mathrm{XXXXY}$ karyotype is thought to arise from maternal non-disjunction during both meiosis I and meiosis II. ${ }^{3-6}$ Such successive non-disjunction theoretically produces an egg with four X chromosomes, which, when fertilised by a $\mathrm{Y}$ bearing sperm, results in an embryo with 49, XXXXY syndrome. ${ }^{3-6}$ Interestingly, the occurrence of this syndrome does not appear to be related to maternal age. Several suggestions have been made to account for the phenotype associated with a $49, \mathrm{XXXXY}$ genotype, as well as for other $\mathrm{X}$ chromosome aneuploidies. Two prevalent theories for the abnormal phenotype include (1) increased dosage of active genes in regions which escape $\mathrm{X}$ inactivation, and (2) asynchronous replication of the extra $X$

Department of Medical and Molecular Genetics, Indiana University School of Medicine, 975

W Walnut Street,

Room IB-264, Indianapolis, IN 46202-5251, USA

J Peet

D D Weaver

G H Vance

Correspondence to: Dr Vance.

Received 24 June 1997 Revised version accepted for publication

3 November 1997

Table 1 Measurements of the three patients reported here

$\mathrm{Wt}=$ weight, $\mathrm{Ht}=$ height, $\mathrm{OFC}=\mathrm{occipitofrontal}$ circumference timing of genes expressed on the $\mathrm{X}$ chromosome is altered.

The classic clinical findings reported in persons with a $49, \mathrm{XXXXY}$ karyotype have included radioulnar synostosis, mental deficiency, and hypogonadism..$^{9-11}$ Because these findings are not distinctive from the clinical findings in Klinefelter syndrome, subjects with $49, \mathrm{XXXXY}$ syndrome are often labelled as having Klinefelter syndrome $(47, \mathrm{XXY})$ or as being a "Klinefelter variant". There are a few reports, however, which do make a point of differentiating this sex chromosome aneuploidy from Klinefelter syndrome. ${ }^{12}{ }^{13}$ After reviewing published reports on $49, \mathrm{XXXXY}$ and examining the three subjects reported in this paper, we have concluded that the $49, \mathrm{XXXXY}$ syndrome should be classified separately from Klinefelter syndrome. People with 49,XXXXY syndrome have characteristic facial features, particular habitus, multiple skeletal anomalies, cardiac defects, genital abnormalities, variable degree of mental impairment, and speech problems apart from those classically seen in Klinefelter syndrome.

\section{Case reports}

CASE 1

Case 1 (Fam No 87398), now a $31 / 2$ year old white male, was referred to the medical genetics service as a neonate following postnatal identification of a $49, \mathrm{XXXXY}$ karyotype. He was born by caesarean section to a nonconsanguineous, 23 year old, $\mathrm{G}(2) \mathrm{P}(1) \mathrm{Ab}(1)$ mother and a 26 year old father. The pregnancy reportedly was complicated by oligohydramnios and intrauterine growth retardation. Apgar scores were 7 at one minute and 8 at five minutes. Length and weight were $<5$ th centile and OFC was greater than $2 \mathrm{SD}$ below the mean (table 1). On examination after birth there were upward slanting palpebral fissures, telecanthus, prominent maxilla, bilateral clinodactyly of the 5 th fingers with converging

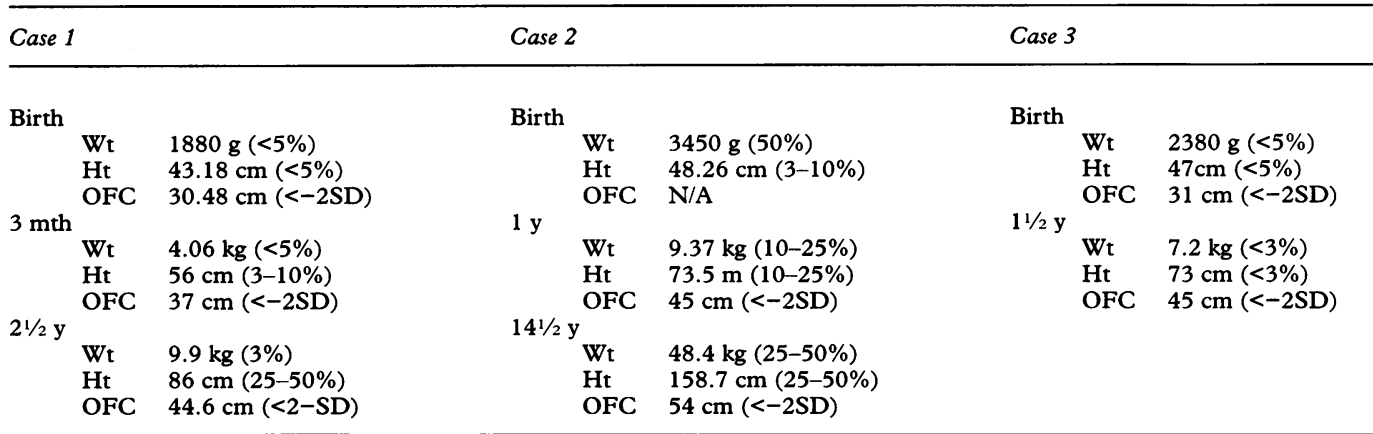




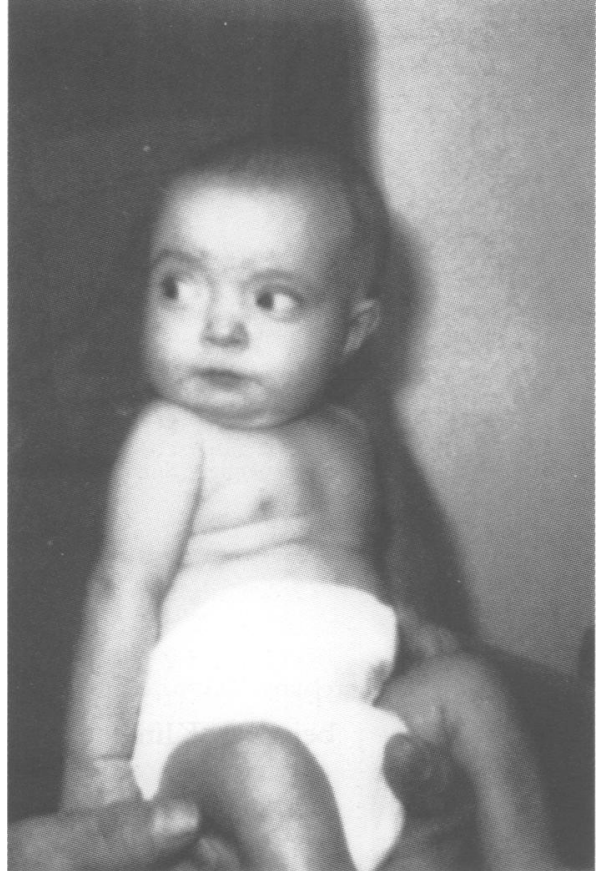

Figure 1 Case 1 aged 3 months.

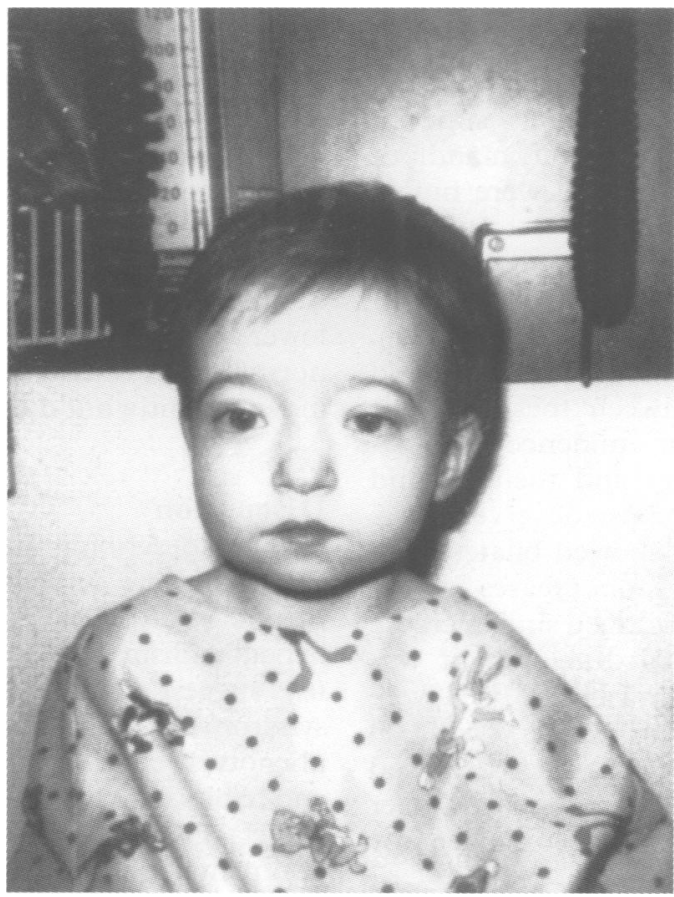

Figure 2 Case 1 aged $21 / 2$ years.

creases, and prominent plantar creases running between the first and second toes bilaterally. There was no limitation to extension or rotation of the elbows. Genital abnormalities included a hypoplastic foreskin, scrotalisation of the penis, small testes, and bilateral hydroceles. Bilateral inguinal hernias and atrial and ventricular septal defects were detected at birth and subsequently repaired successfully. The family history included hyperthyroidism in the father resulting in thyroidectomy, and pectus carinatum in the mother and several of her uncles.

At the age of 3 months, inner and outer canthal distances $(3 \mathrm{~cm}$ and $6 \mathrm{~cm}$, respectively) were both between the 3 rd and 25 th centile and palpebral fissure lengths were both $1.5 \mathrm{~cm}$ (greater than 2 SD above the mean). Additionally, plagiocephaly, a depressed nasal bridge, asymmetrical chest, and clinodactyly of the 2nd toes were noted (fig 1). At the age of 2 years 2 months, both his inner and outer canthal distances were above the 97th centile. Further examination showed an open metopic suture, facial asymmetry, underdeveloped orbital bones, intermittent strabismus, narrow but normally positioned ears, genu valgum, hyperextensible elbows, dermal hyperkeratosis, and generalised hypotonia (fig 2).

Chest radiographs showed stable cardiomegaly, levoscoliosis of the lower thoracic and upper lumbar spine, and a right cervical rib. The scoliosis, thought in part to be secondary to neuromuscular hypotonia, has gradually improved with time, decreasing from $20^{\circ}$ at the age of 1 year to $6^{\circ}$ at the age of 3 .

Case 1 received physical, occupational, and speech therapy from the age of 6 months. Both hearing and vision have been tested and are within normal limits. Developmental assessment at several stages of his life indicated global developmental delay. At 6 months, the Bayley Scales of Infant Development rated the mental development index as $<50$ (age equivalent of 3 months). The behavioural age was assessed at 2.2 months using the Wisconsin Behavior Rating Scale, and between 0-3 months on the Rossetti Infant-Toddler Language Scale. At the age of 1 year, case 1 was evaluated to have gross motor skills at a 4 month level and fine motor skills at a 9 month level. Behavioural age was estimated at 7 months by the Wisconsin Behavior Rating Scale. At a chronological age of 36 months, the Peabody Developmental Motor Scales-Fine Motor Scale estimated an age equivalence of 15 months. Case 1 sat unassisted at 1 year and scooted and stood with help at 2 years of age. At 3 years, his only words were "Mama" and "Dada."

CASE 2

Case 2 (Fam No 54754) was last evaluated by us at the age of $15 \frac{1}{2}$ years. $\mathrm{He}$ is a white male who was born at term to a non-consanguineous, 22 year old, $G(1) P(1)$ mother and a 24 year old father. The pregnancy was uncomplicated. Birth weight was $3450 \mathrm{~g}$ (50th centile) and length was $48 \mathrm{~cm}$ (3rd-10th centile) (table 1). Postnatally, he was found to have tetralogy of Fallot and subsequently underwent ventricular septal defect repair.

Case 2 was ascertained at 1 year of age by karyotype analysis for dysmorphic features and developmental delay. On examination at 1 year, his height and weight were at the 20th to 25th centile range for age and head circumference was greater than $2 \mathrm{SD}$ below the mean (table 1). Physical features included plagiocephaly, low anterior hairline, right preauricular pit, short neck, abnormal palmar creases with bilateral fifth finger clinodactyly, small penis and testes, and delayed bone age. He was lost to follow up until the age of 14 years 2 months, during which time he was reported to have had frequent upper respiratory tract infections with multiple episodes of pneumonia. On physical 
Table 2 A comparison of Klinefelter syndrome, 49,XXXXY syndrome, and the three new patients reported in this paper

\begin{tabular}{|c|c|c|c|c|c|}
\hline & Klinefelter syndrome ${ }^{\star}$ & $49, X X X X Y$ syndromet & Case 1 & Case 2 & Case 3 \\
\hline Intelligence & Normal/slightly reduced & Variable, low normal/MR & DD & DD & DD \\
\hline Speech & Delay & Severe delay, absent & Absent & Absent & Absent \\
\hline Stature & $\begin{array}{l}\text { Average height } \geqslant 184 \mathrm{~cm} \\
+(90-97 \%)\end{array}$ & $\begin{array}{l}\text { Average birth length } 48.6 \mathrm{~cm} \\
(25-50 \%) \text {, average adult } \\
\text { height } 181 \mathrm{~cm}(75-90 \%)\end{array}$ & $25-50 \%$ & $25-50 \%$ & $<3 \%$ \\
\hline Skeletal abnormalities & $\begin{array}{l}\text { Scoliosis, } 5 \text { th finger } \\
\text { clinodactyly }\end{array}$ & $\begin{array}{l}\text { Many anomalies, delayed } \\
\text { ossification, cartilage } \\
\text { degeneration }\end{array}$ & $\begin{array}{l}\text { Plagiocephaly, asymmeterical } \\
\text { chest, levoscoliosis, right } \\
\text { cervical rib, 5th finger } \\
\text { clinodactyly, genu valgum }\end{array}$ & $\begin{array}{l}\text { Plagiocephaly, elbow } \\
\text { contracture, exaggerated } \\
\text { lordosis, } 5 \text { th finger } \\
\text { clinodactyly, phalangeal } \\
\text { hypoplasia, knee enlargement, } \\
\text { genu valgum, pes planus }\end{array}$ & $\begin{array}{l}\text { Trigonocephaly, } \\
\text { hip subluxation }\end{array}$ \\
\hline Cardiovascular defects & $\begin{array}{l}\text { Increased incidence of } \\
\text { MVP }\end{array}$ & $14-20 \% \neq \varnothing$ & ASD,VSD & TOF & PDA \\
\hline Genital abnormalities & Small penis,small testes & Small penis,small testes & $\begin{array}{l}\text { Hypoplastic foreskin, penile } \\
\text { scrotalisation, small testes, } \\
\text { bilateral hydroceles }\end{array}$ & Small penis,small testes & Normal genitalia \\
\hline
\end{tabular}

^Paulsen and Plymate. ${ }^{29}$

†Sijmons et al. . $^{3}$

$\ddagger$ Karsh et al. ${ }^{9}$

\$Linden et al. ${ }^{1 \mathrm{x}}$

$\mathrm{ASD}=$ atrial septal defect, $\mathrm{DD}=$ developmental delay, $\mathrm{MR}=$ mental retardation, $\mathrm{MVP}=$ mitral valve prolapse, $\mathrm{PDA}=$ patent ductus arteriosis, $\mathrm{TOF}=\mathrm{tetralogy}$ of $\mathrm{Fallot}$, $\mathrm{VSD}=$ ventricular septal defect.

examination at 14 years 2 months, his outer canthal distance was $9.25 \mathrm{~cm}$ (75th-97th centile) and inner canthal distance was $3.75 \mathrm{~cm}$ (greater than $2 \mathrm{SD}$ above the mean) with a palpebral fissure length of $2.75 \mathrm{~cm}$ (greater than 2 SD below the mean). Plagiocephaly, epicanthic folds, upward slanting palpebral fissures, prominent nasal bridge, broad and flat nose, left malar flattening, thick superior helices, right sided preauricular pit, mandibular hypoplasia, and micrognathia were noted. Skeletal abnormalities included a raised left shoulder, exaggerated spinal lordosis, contracture of the right elbow, bilateral 5th finger clinodactyly, thin tapering legs with genu valgum, thin and narrow feet with pes planus, and increased sandal gap between toes 1 and 2 bilaterally. Bilateral thenar eminence hypoplasia, clubbing of the finger and toenails, and small penis and testes were also observed. Dermatoglyphic examination showed bilateral hypoplasia of the distal flexion creases of the thumb and fingers with a bridged simian crease on the right palm. Sexual development was Tanner stage II. Both serum LH and FSH were markedly raised, indicating primary gonadal failure. $X$ ray evaluation of the hands showed hypoplasia of the distal phalanx of each finger and a normal bone age. Testosterone therapy was refused by the parents.

Developmental delay of 6-8 months was assessed at a chronological age of 17 months. Case 2 crawled at 2 years and walked at $2 \frac{1}{2}$ years. He has severe speech impairment and communicates primarily by sign language. Hearing and vision are reported as normal.

CASE 3

Case 3 (Fam No 88585) is a $3 \frac{1}{2}$ year old, Amish, white male born by spontaneous vaginal delivery to a 25 year old, $\mathrm{G}(6) \mathrm{P}(3) \mathrm{Ab}$ (3) mother and a 27 year old father. Consanguinity was denied and the pregnancy was uncomplicated. Apgar scores were 8 at one minute and 9 at five minutes. Birth weight and length were at the 5 th centile and his OFC measured greater than 2 SD below the mean (table 1). A patent ductus arteriosus was identified at birth and ligated at 15 months. He had pneumonia at 17 months.
He was referred to the medical genetics clinic following a peripheral blood karyotype report of $49, \mathrm{XXXXY}$. On examination at the age of 18 months, he was a small, pale, and shy child with a triangular shaped head. Both his height $(73 \mathrm{~cm})$ and weight $(7.2 \mathrm{~kg})$ were below the 3 rd centile. Head circumference was greater than $2 \mathrm{SD}$ below the mean (table 1). He had a prominent forehead, horizontal palpebral fissures with drooping lower lids, normal inner and outer canthal measurements, broad nasal bridge, downturned corners of the mouth, an inverted left nipple, and a sacral dimple. Subluxation of the right hip and eversion of the lower legs bilaterally were also noted. He had normal reflexes and truncal hypotonia. He sat independently but did not walk or speak.

\section{Discussion}

Reports describing subjects with $49, \mathrm{XXXXY}$ syndrome have emphasised the "classic triad" of mental retardation, radioulnar synostosis, and hypogonadism..$^{9-11}$ We, and a few others before us, suggest that patients with $49, \mathrm{XXXXY}$ syndrome actually have a more distinctive phenotype consisting of a characteristic facies and habitus, multiple skeletal anomalies, cardiac defects, genital abnormalities, a variable degree of mental impairment, and severe speech impairment (table 2). The clinical phenotype changes as the person grows to an adult. Therefore, certain features present in children are not necessarily present in adults and vice versa.

The characteristic facial appearance of a child with 49,XXXXY syndrome includes a full, round face, epicanthic folds, upward slanting palpebral fissures, ocular hypertelorism, telecanthus, a broad and depressed nasal bridge, and micrognathia. ${ }^{14-16} \mathrm{With}$ age, the fullness of the face gives way to coarsening of features and prognathism becomes apparent. ${ }^{101718}$ Patients may also have microcephaly, cleft palate, and abnormally shaped or positioned ears. ${ }^{12} 1819$ All three of our patients have characteristic facial features and microcephaly (table 3 ). Cases 1 and 2 also have plagiocephaly and facial asymmetry. To our knowledge, plagiocephaly in association with $49, \mathrm{XXXXY}$ syndrome has not been 
Table 3 Facial features observed in the 49, XXXXY syndrome and the three reported patients

\begin{tabular}{llll}
\hline $49, X X X X Y$ & Case 1 & Case 2 & Case 3 \\
\hline Microcephaly & + & + & + \\
Full/round face (childhood) & + & $?$ & - \\
Epicanthic folds & + & + & + \\
Upward slanting palpebral fissures & + & + & - \\
Ocular hypertelorism & + & + & + \\
Telecanthus & + & - & - \\
Broad, depressed nasal bridge & + & + & + \\
Micrognathia & + & + & + \\
Abnormally shaped/positioned ears & + & + & - \\
\hline
\end{tabular}

reported previously, and we found only one published case describing facial asymmetry. ${ }^{16}$

The general adult habitus of a person with $49, \mathrm{XXXXY}$ syndrome is eunuchoid. The neck is short, the shoulders and chest are narrow, and frequently the nipples are widely spaced. ${ }^{1018}$ Patients often have long, thin tapering arms and legs with bilateral cubitus valgus, genu valgus, and pes planus. As with facial features, the body habitus of a subject with $49, \mathrm{XXXXY}$ syndrome changes over his lifetime. Infants with a $49, \mathrm{XXXXY}$ karyotype are generally small for gestational age yet may show "catch up" growth later in life. For example, the birth length of case 1 was below the 5 th centile but measured between the 25 th and 50 th centiles at the age of $2 \frac{1 / 2}{2}$ years. However, the birth length of case 3 was also below the 5 th centile and remained so at 18 months of age. Case 2 had a normal birth length and measured between the 25 th and 50 th centiles for height at the age of $141 / 2$ years. A review of heights and weights of published cases of 49,XXXXY syndrome (not including our three cases) showed an average birth weight of $2551 \mathrm{~g}(<10$ th centile, $n=29)$ and average birth length of $48.6 \mathrm{~cm}$ (25th-50th centile, $n=8$ ). The average adult height was $181 \mathrm{~cm}$ (75th-90th centile, $\mathrm{n}=6$ ) and average adult weight was $71 \mathrm{~kg}$ (75th-90th centile, $n=4)$.

Multiple skeletal anomalies occur in people with $49, \mathrm{XXXXY}$ syndrome and include radioulnar synostosis, delayed bone age with lack of closure of bone growth plates into adulthood, congenital hip dislocation, early degeneration of articular cartilage (especially at the elbows), and hypertrophy of epiphyses. ${ }^{2023}$ The skeletal anomalies of the three cases reported are listed in table 2 . Case 1 had plagiocephaly, a right cervical rib, asymmetrical chest, scoliosis, and bilateral 5th finger clinodactyly. Case 2 had plagiocephaly, a raised left shoulder, exaggerated spinal lordosis, contracture of the right elbow, hypoplasia of the phalanges, bilateral 5 th finger clinodactyly, genu valgum, and pes planus. Case 3 had congenital hip subluxation.

Congenital heart and vascular disease is also observed in subjects with a $49, \mathrm{XXXXY}$ karyotype. In fact, the first case report by Fraccaro et $a l^{1}$ described a child with a patent ductus arteriosus (PDA). Fifteen years later, Karsh et al ${ }^{9}$ reviewed published reports and found that 13 of $88(14 \%)$ reported cases of $49, \mathrm{XXXXY}$ syndrome had a cardiovascular defect with the most common defect being a PDA. Several reports since 1975 have also described congenital heart defects. ${ }^{451819}$ To these reported cases we add three new patients. Case 1 was born with atrial and ventricular septal defects, case 2 was born with tetralogy of Fallot, and case 3 with a PDA. Interestingly, Meschede $e t$ $a l^{4}$ reviewed published reports of another sex aneuploidy syndrome, 48,XXYY, and found that $8 \%$ of those examined had a congenital heart defect.

Genital abnormalities are consistently found in males with a $49, \mathrm{XXXXY}$ karyotype. These anomalies include small penis and testes, undescended testes, bifid scrotum, ambiguous genitalia, and scrotalisation of the penis. ${ }^{13182526}$ Two of our patients had hypogonadism and case 1 also had scrotalisation of the penis, hypoplastic foreskin, and bilateral hydroceles.

Another feature of $49, \mathrm{XXXXY}$ syndrome is cognitive impairment. Most authors of older publications predicted a bleak prognosis of moderate to severe mental retardation in these subjects with an estimated mean IQ of $35 .^{21326}$ While patients with moderate to severe mental retardation and this karyotype do exist and will continue to be reported, the above prediction of IQ range probably is based on biased data. Many of the patients in the earlier reports were institutionalised and did not receive sufficient early intervention or personal interaction which might have enabled them to function at a higher level. More recently, several patients have been reported with IQs in the borderline to low normal range. Sheridan $e t a l^{6}$ described a patient with IQs of 76 and 70 when assessed by the Stanford Binet and Weschler Preschool and Primary Scale of Intelligence (WPPSI) tests, respectively. Borghgraef et al ${ }^{13}$ reported two patients, both of whom had IQs of 72 as measured by WPPSI scale. Kleczkowsa et at reported two additional patients with borderline IQs of 70 and 72. Lomelino and Reiss ${ }^{27}$ reported a child with $49, \mathrm{XXXXY}$ syndrome who was ascertained only as a control to a research study. This child had an IQ of $78 \pm 6$ as measured by the Stanford-Binet test at 4 years 10 months. Of the three cases reported here, formal developmental data were available only from case 1 . However, all three were documented to have developmental delay.

Additionally, speech impairment or even speech aphasia is uniformly found in persons with 49, XXXXY syndrome. ${ }^{12}{ }^{15} 26-28$ Each patient reported here had significant speech impairment. Neither cases 1 nor 2 attempt purposeful verbal communication. Case 2 has successfully learned and uses sign language. Case 3, at 18 months, also had significant speech delay.

In conclusion, we believe that $49, \mathrm{XXXXY}$ syndrome is a distinct clinical entity and should not be "lumped" together with Klinefelter syndrome. People with $49, \mathrm{XXXXY}$ syndrome have distinctive facial features, are more mentally handicapped, and have greater speech difficulty than those with Klinefelter syndrome. In addition, males with $49, \mathrm{XXXXY}$ syndrome are generally shorter, have distinct skeletal anomalies, and an increased incidence of congenital heart defects when compared to males with a $47, \mathrm{XXY}$ karyotype. The presence of congenital heart defects in subjects with 
$49, \mathrm{XXXXY}$ syndrome suggests special attention be given to the cardiac evaluation. Conversely, males with congenital heart defects who fit the phenotypic description of $49, \mathrm{XXXXY}$ syndrome or who have significant speech impairment or both are candidates for chromosome analysis.

1 Fraccaro M, Kaijser K, Lindsten G. A child with 49 chromosomes. Lancet 1960;ii: 899-902.

2 Kleczkowska A, Fryns JP, Van den Berghe $H$ $\mathrm{X}$-chromosome polysomy in the male. Hum Genet $1988 ; 80$ $16-22$

3 Villamar M, Benitez J, Fernandez E, Ayuso C, Ramos C. Parental origin of chromosomal nondisjunction in a $49, X X X X Y$ male using recombinant-DNA techniques. Clin Genet 1989;36:152-5.

4 Deng HX, Abe K, Kondo I, et al. Parental origin and mechanism of formation of polysomy $\mathrm{X}$ : an XXXXX case and anism of formation of polysomy X: an XXXXX case and four XXXXY cas

5 Huang THM, Greenberg F, Ledbetter DH. Determination of the origin of nondisjunction in a $49, \mathrm{XXXXY}$ male using hypervariable dinucleotide repeat sequences. Hum Genet 1991;86:619-20.

6 Leal CA, Belmont JW, Nachtman R, Cantu JM, Medina C. Parental origin of the extra chromosomes in polysomy $\mathrm{X}$. Hum Genet 1994;94:423-6.

7 Scheres JMJC, Merkx GFM, Hustin TWJ. Prometaphase banding of human chromosomes with basic fuchsin. Hum Genet 1982;61:8-11.

8 Sarto GE, Otto PG, Kuhn EM, Therman E. What causes the abnormal phenotype in a $49, \mathrm{XXXXY}$ male? Hum Genet 1987;76:1-4.

9 Karsh RB, Knapp RF, Nora JJ, Wolfe RR, Robinson A. Congenital heart disease in $49, \mathrm{XXXXY}$ syndrome. Pediat rics 1975;56:462-4.

10 Tenbrinck MS, Boyd JH, Buchin SY. The chromosome 49, XXXXY syndrome. Arizona Med 1976;33:546-50.

11 Singh TH, S Rajkowa. 49,XXXXY chromosome anomaly: an unusual variant of Klinefelter's syndrome. Br $\mathcal{F}$ Psych 1986;148:209-10.

12 Zaleski WA, Houston CS, Pozsonyi J, Ying KL. The XXXXY chromosome anomaly: report of three new cases and review of 30 cases from the literature. Can Med Assoc $\mathcal{F}$ 1966;94:1143-54.
13 Borghgraef M, Fryns JP, Smeets E, Marien J, Van den Berghe $\mathrm{H}$. The 49, XXXXY syndrome: clinical and psychological follow-up data. Clin Genet 1988;33:429-34.

14 Hayeka A, Riccardi V, Atkins L, Hendren H. 49, XXXXY chromosomal anomaly in a neonate. $f$ Med Genet 1971;8:220-1.

15 Moric-Petrovic S, Laca Z, Markovic S, Markovic V. $49, \mathrm{XXXXY}$ karyotype in a mentally retarded boy. $\mathcal{f}$ Ment Defic Res 1973;17:73-80.

16 Kushnick T, Colondrillo M. 49, XXXXY patient with hemifacial microsomia. Clin Genet 1975;7:442-8.

17 Cowie VA, Singh RR, Wheater R. 49,XXXXY chromosome anomaly in a mentally retarded man. Br $\mathcal{F}$ Psych 1986;148: 210-12.

18 Linden MG, Bender BG, Robinson A. Sex chromosome tetrasomy and pentasomy. Pediatrics 1995;96:672-82.

19 Curfs LMG, Schreppers-Tijdink G, Wiegars A, Borghgrae $M$, Fryns JP. The 49, XXXXY syndrome: clinical and psychological findings in five patients. 7 Ment Defic Res 1990; 34:277-82.

20 Sergovich F, Uilenberg C, Pozsonyi J. The 49, XXXXX chromosome constitution: similarities to the $49, \mathrm{XXXXY}$ condition. $\mathcal{F}$ Pediatrics 1971;78:285-90.

21 Schmidt R, Pajewski M, Malka R. Epiphysial dysplasia: a constant finding in the XXXXY syndrome. 7 Med Genet 1978;15:282-7.

22 Tumba A, Laredo JD, Corvol MT, et al. Evolution of bone anomalies in 49,XXXXY syndrome. Can Assoc Radiol $\mathcal{F}$ 1993;44:107-11.

23 Sijmons RH, van Essen AJ, Visser JD, et al. Congenital knee dislocation in a 49, XXXXY boy. $\mathcal{F}$ Med Genet 1995;32:30911.

24 Meschede $\mathrm{D}$, Nekarda $\mathrm{T}$, Kececioglu $\mathrm{D}$, et al. Congenital heart disease in the 48,XXYY syndrome. Clin Genet 1995; 48:100-2.

25 Hecht F Observations on the natural history of $49, \mathrm{XXXXY}$ individuals. Am $\mathcal{F}$ Med Genet 1982;13:335-6.

26 Sheridan MK, Radlinski SS, Kennedy MD. Developmental outcome in 49,XXXXY Klineflelter syndrome. Dev Med Child Neurol 1990;32:528-46.

27 Lomelino CA, Reiss AL. 49, XXXXY syndrome: behavioural and developmental profiles. F Med Genet 1991;28: 609-12.

28 Pallister PD. 49,XXXXY syndrome. Am 7 Med Genet 1982. 13:337-9.

29 Paulson CA, Plymate SR. Klinefelter's syndrome. In: King RA, Rotter JI, Motulsky AG, eds. The genetic basis of common diseases. NewYork: Oxford University Press, 1992: 876-94 